\title{
ESTUDO DOS NEURÔNIOS DO PLEXO CARDÍACO NA INFECÇÃO AGUDA PELO TRYPANOSOMA CRUZI EM RATOS ALBINOS
}

\author{
Edmundo Chapadeiro, Paulo Sérgio S. Beraldo, Paulo Cesar Jesus, Patrícia \\ Dias Fernandes e Luiz Fernando Junqueira Júnior
}

\begin{abstract}
O estudo histológico do plexo nervoso autonômico do coração de ratos albinos, na fase aguda da infeç̧ão pelo Trypanosoma crụi, mostrou ganglionite, periganglionite e neurite de intensidades variáveis. Entretanto, a contagem dos neurônios dos gânglios não revelou redução (denervação) significativa dos mesmos.
\end{abstract}

Palavras-chaves: Infecçãochagásica aguda experimental. Denervaçãocärdiaca. Contagem neuronal.

$\mathrm{Na}$ tentativa de correlacionar a denervação parassimpática com a disfunção autonômica cardíaca do rato, cronicamente infectado pelo Trypanosoma cruzi ( $T$. cruzi), não se observou destruição significativa dos neurônios do plexo cardiaco ${ }^{2}$. Este achado sugere que na infecção chagásica aguda do modelo em estudo não ocorreria denervação do coração como admite Alcântara (1961) ${ }^{1}$.

A finalidade deste trabalho é a de analisar o comportamento do citado plexo, através da análise histológica e da contagem dos neurônios dos gânglios cardíacos do rato na fase aguda da infecção pelo $T$. cruzi.

\section{MATERIAL E MÉTODOS}

Consta de cinco ratos albinos Wistar, infectados intraperitonealmente com 2.000 a 6.000 formas sanguícolas das cepas Y e São Felipe (12SF) do $T$. cruzi e de cinco ratos, não infectados, nas mesmas condições, que serviram de controle.

Os animais infectados e os controles foram sacrificados entre o $21^{\circ}$ e $30^{\circ}$ dias do experimento (fase aguda).

Cortes histológicos do coração, de $7 \mu \mathrm{m}$ de espessura, foram obtidos e montados segundo a

\footnotetext{
Laboratório Cardiovascular da Faculdade de Ciências da Saúde da Universidade de Brasilia, Brasília, DF e Curso de Pósgraduação em Patologia Humana da Faculdade de Medicina do Triângulo Mineiro, Uberaba, MG.

Endereço para correspondência: Prof. Edmundo Chapadeiro. Curso de Pós-graduação em Patologia Humana/FMTM. Av. Getúlio Guaritá 130, 38025-440 Uberaba, MG, Brasil.

Recebido para publicação em $21 / 12 / 93$.
}

técnica do trabalho anterior ${ }^{2}$ e corados pela hematoxilina-eosina $(\mathrm{HE})$ para análise microscópica e contagem dos neurônios. A contagem destes, incluiu neurônios íntegros e aqueles com sinais degenerativos; neurônios com sinais de morte não foram computados.

Para comparação estatística entre os valores obtidos foi aplicado o teste não paramétrico de Kruskall-Wallis, adotando-se, para fins de conclusão, o nível de significância $\mathrm{p}=0,05$.

\section{RESULTADOS}

A análise histológica dos corações dos animais infectados revelou cardite aguda multifocal ou difusa, atingindo simultaneamente o epicárdio, endocárdio e miocárdio, com parasitismo variável. Os gânglios e filetes nervosos do plexo cardíaco, situados principalmente na parede dos átrios eram também atingidos pelo mesmo processo inflamatório, caracterizado por infiltrado de mononucleares e raros granulócitos. Alguns neurônios apresentavam fenômenos degenerativos (vacuolização, retração, hipo e hipercromasia citoplasmática) e atrofia de intensidade variáveis; sinais de necrose e substituição por células satélites (satelitose) eram escassos; entretanto, a maioria dos neurônios parecia normal (Figuras 1 e 2).

O resultado da contagem do número total dos neurônios (íntegros e degenerados), do coração dos animais infectados e dos controles, encontra-se na Tabela 1. A análise estatística não mostrou diferença significativa entre o número de neurônios nos dois grupos $(p=0,437274)$. 
Chapadeiro E, Beraldo PSS, Jesus PC, Fernandes PD, Junqueira Júnior LF. Estudo dos neurônios do plexo cardiaco na infecção aguda pelo Trypanosoma cruzi em ratos albinos. Revista da Sociedade Brasileira de Medicina Tropical 27:79-81, abr-jun, 1994.

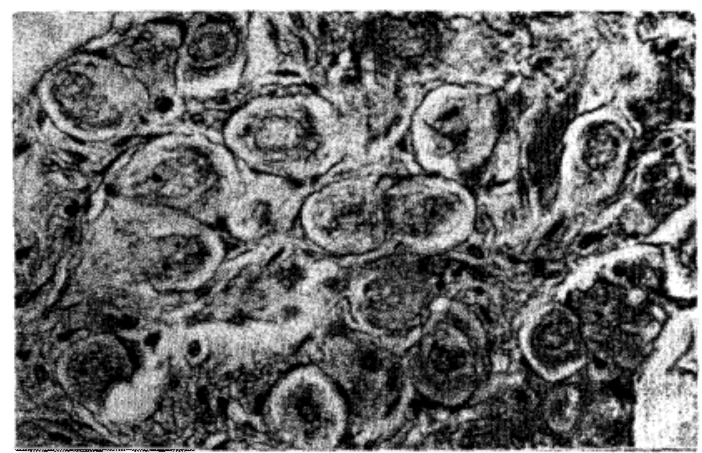

Figura 1 - Gânglio atrial de rato controle. HE $x 400$.

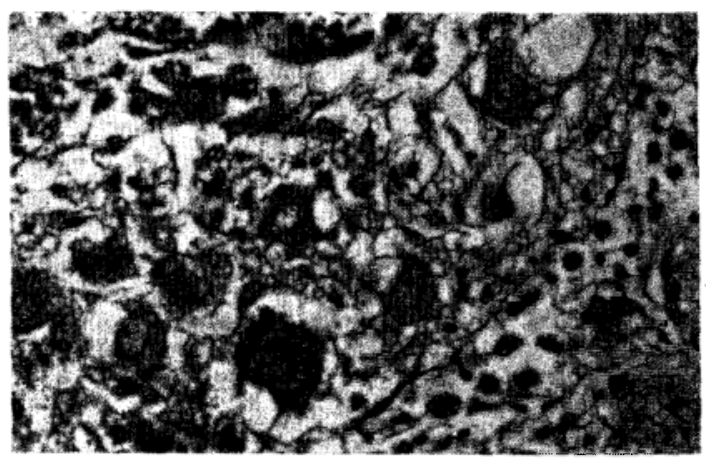

Figura 2 - Gânglioatrial de rato chagásico. Ganglionite com fenômenos degenerativos dos neurônios. HE $x 400$.

Tabela 1 - Contagem dos neurônios intracardíacos de ratos infectados pelas cepas Ye São Felipe (12SF) e de controles.

\begin{tabular}{lcccccc}
\hline \multicolumn{3}{c}{ Ratos chagásicos } & & \multicolumn{3}{c}{ Ratos controles } \\
\cline { 7 - 8 } protocolo & ganglionite & $\mathrm{n}^{0}$ neurônios & & protocolo & ganglionite & $\mathbf{n}^{\mathbf{0}}$ neurônios \\
\hline Y7DV 2.46 & +++ & 1962 & & N1ET 3.20 & 0 & 2258 \\
Y7DET 2.41 & ++ & 4030 & & N2DPEA 3.22 & 0 & 3444 \\
Y7ET 2.15 & ++ & 3696 & & N2DT 3.24 & 0 & 2418 \\
SF6DTEA 1.29 & +++ & 3301 & & N2EV 3.18 & 0 & 5350 \\
SF6EP 1.32 & +++ & 2163 & & N2DEV 3.29 & 0 & 4909 \\
\hline Média & & 3248 & & & 3676 \\
\hline
\end{tabular}

$\mathrm{P}=0,437274$

\section{DISCUSSÃO}

Embora as lesões do sistema nervoso autônomo cardíaco (ganglionite, periganglionite e neurite) fossem intensas nos animais infectados pelo $T$. cruzi, não houve destruição (denervação) significativa dos neurônios dos gânglios. A escassa destruição neurọal na fase aguda, da infecção do rato albino, explica porque tal fenômeno não foi * constatado na fase crônica ${ }^{2}$.

A diferença éntre nossos achados e os de Alcântara ${ }^{d}$ parece depender da metodologia empregada: no trabalho desse autor foram computados, separadamente, "neurônios aparentemente normais" e "neurônios lesados (degenerados e necrosados)", enquanto computamos, simultaneamente, neurônios normais e neurônios com sinais degenerativos, mas não necrosados. A presença de neurônios com sinais de degeneração não significa perda neuronal e da função do coração, visto que, como se sabe, células degeneradas são capazes de manter suas funções normais (p.ex., os hepatócitos na esteatose hepática); ressalte-se que na cardite chagásica do camundongo ${ }^{6}$, neurônios degenerados ou com sinais de necrose, podem coexistir ao lado de neurônios hipertróficos e, portanto, capazes de compensar o déficit da função. De fato, na fase aguda deste mesmo modelo, o átrio do coração não mostrou hipersensibilidade do tipo pós-denervação à acetilcolina exógena ${ }^{8}$. A diferença dos achados poderia ainda ser explicada pelo não tratamento estatístico dos dados de Alcântara ${ }^{1}$.

Pelo exposto, não parece claro, porque no rato, embora sejam intensas as lesões inflamatórias do plexo, tanto na fase aguda como na fase crônica da infecção pelo T. cruzi, não ocorre destruiçãoneuronal (denervação) significativa. Talvez diferentes mecanismos de destruição possam explicar a discrepância entre o que ocorre no modelo em estudo e no homem ${ }^{3} 45$. 
Chapadeiro E, Beraldo PSS, Jesus PC, Fernandes PD, Junqueira Júnior LF. Estudo dos neurônios do plexo cardíaco na infecção aguda pelo Trypanosoma cruzi em ratos albinos. Revista da Sociedade Brasileira de Medicina Tropical 27:79-81, abr-jun, 1994.

\section{SUMMARY}

Microscopic investigation of parasympathetic heart nervous plexus of the albino rat in the acute phase of Trypanosona cruzi infection showed ganglionitis, periganglionitis and neuritis of variable degree; despite the degenerative changes, no significant reduction of ganglion neurons was observed, when compared with controls.

Key-words: Experimental acute chagasic infection. Cardiac denervation. Neuronal count.

\section{AGRADECIMENTOS}

A Alessandra Scoda, Luzia Helena Gonçalves dos Santos e Valéria Ramos, pelo valioso auxílio prestado.

\section{REFERÊNCIAS BIBLIOGRÁFICAS}

1. Alcântara FG. Sistema neurovegetativo do coração na moléstia de Chagas experimental. Revista Goiana de Medicina 7:111-126, 1961.

2. Chapadeiro E, Florêncio RFC, Afonso PC, Beraldo PSS, Jesus PC, Junqueira Jr LF. Neuronal counting and parasympathetic disfunction of heart chronically Trypanosoma cruzi infected rats. Revista do Instituto de Medicina Tropical de São Paulo 33:337-341, 1991.

3. Köberle F. Patologia da moléstia de Chagas. Revista Goiana de Medicina 3:155-179, 1957.

4. Köberle F. Chagas' disease and Chagas' syndrome. The pathology of American trypanosomiasis. In: Dawes B (ed) Advances in parasitology, Academic Press, New York, vol.6, p.63, 1968.

5. Köberle F. Cardiopathia parasympathicopriva. Munch Med Wochenschr 101:1308-1310, 1959.

6. Lopes ER, Tafuri WL. Involvement of the autonomic nervous system in Chagas heart disease. Revista da Sociedade Brasileira de Medicina Tropical 16:206212, 1983.

7. Oliveira JSM. A concentração de noradrenalina miocárdica em ratos sob diversas condições experimentais com destaque à infecção pelo $T$. cruzi. Tese de Mestrado, Faculdade de Medicina de Ribeirão Preto da Universidade de São Paulo, Ribeirão Preto, 1977.

8. Pires JGP, Lima Pereira FE. Absence of supersensitivity to the negative chronotropic effect of acetylcholine in atria of mice acutely infected with Trypanosoma cruzi, CL strain. Revista da Sociedade Brasileira de Medicina Tropical 24:259-261, 1991. 